\title{
The assessment of Bosnian EFL learners' knowledge by two different measures: test and writing assignment
}

\author{
Ana Tankosić \& Vildana Dubravac \\ International Burch University, Sarajevo
}

\begin{abstract}
English is taught as a foreign language in elementary and high schools in Bosnia and Herzegovina $(\mathrm{BIH})$. However, since the number of English classes per week is very limited they should be utilized in the best possible way to produce proficient users of English. Nowadays, when language proficiency is viewed as one's ability to speak and write in the target language and not about it, the need for the proficiency evaluation in schools arises. The present study attempts to shed a spot of light on this issue, investigating two very common ways of assessing students' knowledge in schools, namely tests and writing assignments. Hence, through the interviews with English teachers and the analysis of students' tests and writing assignments, the current paper explores the ways in which these two measures are realized, the tasks they consist of, the type of linguistic knowledge they are used to evaluate, their levels of difficulty, and the type of corrective feedback teachers provide on both of them. The results suggest that teachers on both measure rather students' explicit than their implicit knowledge, focusing much more on accuracy than fluency development.
\end{abstract}

Key words: assessment; test; writing assignment; corrective feedback; EFL.

\section{Introduction}

English as a lingua franca is considered to be a language of the world. It connects different societies and cultures, and therefore, enhances economic, political and social life of the world's population. Bosnia and Herzegovina (BIH) is a developing country whose citizens are mostly well acquainted with the English language, primarily because they are aware of its importance for the touristic and other advancements needed for the prosperity of their country. Moreover, English is one of the best mediums for the retrieval of information, and it is possibly the best human asset. We are exposed to English via the media (e.g. TV, radio, the Internet, etc.), therefore, the reason why this language should be known, which is being up-todate, is also an aid in its acquisition.

Other than the acquisition of English via the media, it is the first foreign language in most elementary and high schools in BIH (Imamović \& Delibegović 
Džanić, 2016). However, a very limited number of hours per week (two or three) might entail the assumption that much attention should be paid to utilize them effectively. An important issue in language development within formal education is the way in which knowledge is evaluated, i.e. which aspects are given primacy while assessing learners' knowledge of a foreign language. The choice of tasks on different measures might indicate the teachers' expectations from students, whether they expect the students mainly to acquire some grammar rules and apply them completing sentences provided outside of the context, or they encourage their students to use the language in the way they would likely use it outside of the classroom, communicating in it. In other words, the measures show whether teachers encourage their learners' explicit or implicit linguistic knowledge development. Grading and feedback might, furthermore, illustrate whether the focus is on fluency or accuracy development.

Therefore, a detailed insight into the ways in which language knowledge is usually evaluated might provide useful information about the way in which the language is learned within language classrooms. The present paper attempts to address this matter exploring two very common assessment methods in English language classrooms, namely tests and writing assignments. The study investigates the way in which they are realized, the tasks they consist of, language skills they evaluate and the way teachers' feedback is provided. Moreover, all the aforementioned issues are studied in both elementary and high schools to investigate the differences.

It is a common practice to introduce a test in the first year of learning the English language in school (in our context usually in the third grade of elementary school), whereas a writing assignment becomes a part of the syllabi usually in the fifth grade of elementary school. While the former usually focuses on measuring accuracy and students' explicit knowledge, the latter is supposed to measure both fluency and accuracy in the English language, showing a great potential for measuring students' implicit knowledge. This study investigates to what extent these assumptions are true. Firstly, the research indicates whether a test in Bosnian EFL context serves mainly to evaluate learners' accuracy and their explicit linguistic knowledge, whether metalinguistic knowledge is expected from learners, as well as how and to what extent the communicative aspect of language learning is incorporated in tests. Furthermore, the research will show how teachers perceive the other very common measure of learners' knowledge, a writing assignment, whether they expect their students to be perfectly fluent and/or accurate in their writing assignments and whether the focus of feedback is on language forms or on the meaning of the message conveyed.

Since no similar investigation has been conducted on this matter in our context, this one is expected to enlighten this very important aspect of language learning, and thus contribute to its improvement and reconsideration. 


\section{Literature review}

It is considered that linguistic knowledge might be of two types which have stood out throughout the history as acquisition vs. learning (Krashen, 1982); procedural vs. declarative knowledge (Anderson, 1983); implicit vs. explicit knowledge (Ellis, N. 2005; Ellis, R., 2005). Krashen (1982) was among the first scholars who made a clear distinction between implicit acquisition and explicit learning of a language. He argued that second language (L2) learners exposed to the GrammarTranslation method had greater knowledge about a language than native speakers. However, their knowledge of grammar was of no use to them in conversation in the target language. Therefore, he ascertained that "language acquisition is a subconscious process and it results in acquired competence, [while] learning is a conscious knowledge of a second language known to most people as 'grammar' or 'rules'" (p. 10).

Anderson's Adaptive Control of Thought (1983) was a ground theory for the most effective version of the skill acquisition theory, which defines learning "as the gradual transformation of performance from controlled to automatic" (Ortega, 2009: 84). That is to say, it converges declarative to procedural knowledge (Anderson, 1983), which is to be used in a spontaneous everyday conversation. Similarly, others (e.g. Ellis, R., 1994, 2005; Ellis, N., 2008) in their analysis of linguistic knowledge differ between explicit and implicit linguistic knowledge. Ellis, N. (2008: 121) makes a distinction between different types of knowledge defining explicit knowledge as "a more conscious operation where the individual tests hypotheses in a search for structure," while implicit knowledge is "a knowledge about the underlying structure of a complex stimulus environment by a process which takes place naturally and without conscious operations."

In addition to the aforementioned contrasting types of linguistic knowledge, Chomsky's competence vs. performance (1965) cannot be omitted. Chomsky identified competence as the "speaker-hearer's knowledge of his language," while he said that its counterpart performance is the "actual use of language in concrete situations" (Chomsky, 1965: 4). We say that speakers have linguistic competence when they are able to "produce and understand an unlimited number of utterances, including many that are novel and unfamiliar, and at the same time they are able to recognize that certain utterances are not acceptable and simply do not belong in their language" (O'Grady et al, 2011: 5-6). Linguists concentrate on the mental system called grammar that helps us interpret sounds, words and sentences. O'Grady et al. (2011) break down grammar into the following components: phonetics, phonology, morphology, syntax and semantics, calling the ability to explain and have knowledge of each of these components metalanguage or metalinguistic competence.

Generally, it is agreed that, with the focus on the communicative aspect of language teaching and learning, students have most benefits of implicit knowledge, 
easily accessed and used in everyday communication. However, due to all characteristics of second and especially foreign language learning explicit knowledge is more likely to be developed, and learners seem to have some benefits from it (see Bialystok, 1978; DeKeyser, 1997; Ellis, N., 2005; Ellis, R. 1997; Lightbown et al., 1993; Lightbown \& Spada, 2008; Muranoi, 2000; Schmidt, 2010), while metalinguistic knowledge appears to be of very limited use (see Han \& Ellis, 1998). Therefore, it seems that efforts should be primarily made in terms of implicit knowledge development. Some attention might also be paid to explicit knowledge development, since it enhances learners' noticing of some regularities in the target language, leading eventually to the correct use of language. Nonetheless, metalinguistic knowledge should not be focused on so much, since learners seem to have almost no benefits from it while communicating in the target language.

The previous research on these two types of knowledge in Bosnian context (see Dubravac \& Pavičić Takač, 2013; Dubravac, 2013; Habibić \& Dubravac, 2017) has indicated that explicit language learning is still dominant within classrooms resulting in the prevalence of explicit over implicit knowledge. The studies have also suggested that although metalinguistic knowledge seems to be greatly encouraged, students still demonstrate a poor knowledge of technical terms used to describe the language. The present study will further clarify this matter analyzing one aspect unexplored so far. It will show which of the two types of linguistic knowledge students are expected to demonstrate on both measures, following the suggestion (Ellis, R., 2005) that explicit knowledge is measured if students rely on grammar rules, their attention is focused on the form while metalinguistic knowledge is encouraged. On the other hand, if students reply relying on the feeling, with their attention directed to the meaning with no use of metalanguage, they tap into their implicit knowledge.

The focus on these two types of linguistic knowledge within classrooms is closely related to accuracy- and fluency-based activities. One of the very first scholars who introduced this dichotomy was Brumfit (1984) who made a distinction between fluency and accuracy oriented activities. The former are expected to encourage voluntary oral production of a second language, while in the case of the latter the emphasis is on the linguistic form and they supervise learners' production of language structures that need to be grammatically correct in the second language (Housen \& Kuiken, 2009). The attainment of accuracy denotes the capability to speak correctly without errors (Lennon, 1990), and it usually requires explicit learning. Fluency, on the other hand, is defined as the capability to manage the second language at the same rate as native speakers (Lennon, 1990), which, as such, implies the use of implicit knowledge. Although both, accuracy and fluency, appear to be developed within classrooms, one of them usually prevails being more encouraged. Throughout the history accuracy was more dominant, while as the need for the use of language in communication appeared, fluency became more accentuated. Gatbonton \& Segalowitz (2005) emphasize that even though 
many teachers claim to follow the communicative way of teaching, their focus is still primarily on accuracy, so there is much to do to shift the focus more onto fluency, so to encourage both. The way of developing them is also evident in the type of feedback teachers provide after some errors are committed.

Teachers have different preferences when it comes to error correction. Their feedback varies in the extent of explicitness or implicitness it demands (Ortega, 2009). It can be form- or meaning-oriented, the former being more present if the aim is accuracy development and the latter if fluency development is seen as the objective of language learning. Three most commonly applied techniques of error correction are self-correction, peer correction and teacher correction. In written measures of students' knowledge, teacher correction prevails, although teachers might provide feedback in different ways: by correcting the errors or by underlining the incorrect structures, by highlighting them or writing some notes, thus promoting self-correction and independent language development.

Error correction in writing focused on language forms has been proved as very effective exerting a profound impact on learners' accuracy (see Chandler, 2000; Ferris, 1995; Sheppard, 1992, etc.). However, not much research has analyzed the other elements of writing, namely fluency, grammatical complexity and lexical complexity (for the other aspects see Wolfe-Quintero et al., 1998), which are also considered important characteristics of a written text.

Whatever the feedback appears to be based on it should be process- and not only product-oriented. The learners' production of language should serve not only for grading but primarily for encouraging the further development. Similarly, when discussing essay assessment Bacha (2001) distinguishes between holistic scoring as the one whose primary purpose is to determine written proficiency level of students and analytic scoring that provides criterion referenced evaluation which observes the advancement of students and assesses their proficiency level in order to upgrade them. She adds that analytic scoring has appeared to be more suitable and convenient for evaluation of the writing skill and all its parts.

The present study will reveal the way in which teachers in BIH use tests and writing assignments to measure their students' knowledge of English, whether they follow the current trends encouraging development of different aspects of communicative competence or they still follow the traditional approach in which accuracy is considered to have a pivotal role.

\section{Method}

\subsection{Instrument and procedure}

The current study was carried out in the period from December 2016 to February 2017. The instruments used to gather data were a semi-structured interview with 
English teachers, and students' tests and writing assignments in the English language course. Therefore, a mixed method was used.

Firstly, a qualitative method was used for the analysis of the interviews with the teachers in order to gather in-depth information about the background of the assessment methods and then tests and writing assignments were examined for the purpose of learning the tasks they consisted of, the way students' knowledge demonstrated on the two measures was assessed and the way in which feedback was provided. The interviews were recorded, and afterwards, their transcript was written. The first section of the interview collected biographical data about the interviewees, while the second section collected main data important for answering the research questions.

Secondly, a quantitative method was used to test the statistical difference and correlation between the grades students got on tests and writing assignments. Computer program used for the statistical data analysis was PASW Statistics 18.

\subsection{Participants and the sample}

Participants in this study were selected using a concurrent sampling method. Purposeful sampling was used for the qualitative part, and probability sampling was used for the quantitative part of the study. The participants in the qualitative part were 9 teachers of English in BIH, teaching in different cities and schools across BIH. 4 of them taught in an elementary, and 5 in a high school. With regard to the gender of the participants 6 were female and 3 were male. Their age range was from 30 to 52, with a mean age of 36. The range of the participants' years of experience in teaching English language was from 1 to 23 with a mean length of 12.89 years. Relevant demographic information about the participants for this study can be found in Table 1.

Table 1. Demographic information about the teachers of elementary and high school

\begin{tabular}{llll}
\hline Participant & Gender & \multicolumn{1}{c}{ City } & \multicolumn{1}{c}{ School level } \\
\hline Participant 1 & Female & Zavidovići & Elementary school \\
Participant 2 & Female & Maglaj & Elementary school \\
Participant 3 & Female & Visoko & High school \\
Participant 4 & Female & Novi Travnik & Elementary school \\
Participant 5 & Male & Zenica & High school \\
Participant 6 & Female & Živinice & Elementary school \\
Participant 7 & Male & Sarajevo & High school \\
Participant 8 & Male & Sarajevo & High school \\
Participant 9 & Female & Hadžići & High school \\
\hline
\end{tabular}


The sample for the quantitative part of this study consisted of 96 tests and writing assignments from 96 students attending 9 aforementioned schools in BIH. The teachers, participants of this study, provided the students' papers for the purposes of the research. The papers were provided from 45 students of elementary school $(46.9 \%)$ (5th $^{\text {th }} 8^{\text {th }}$ grade students), and 51 students of high school $(53.1 \%) \quad 2^{\text {nd }}$ to $4^{\text {th }}$ grade students).

\subsection{Research questions}

The current study was guided by the following research questions:

1. What types of tasks do teachers include on tests?

2. What is the type of feedback teachers give to students, and does it differ on individual basis?

3. What is more demanding for students: tests or writing assignments?

4. Is there a statistically significant difference between the grades students get on tests and writing assignments?

5. Is there a statistically significant difference between the grades on writing assignments with regard to school level?

6. Is there a statistically significant difference between the grades on tests with regard to school level?

7. Is there a statistically significant correlation between students' grades on tests and writing assignments?

\section{Results and discussion}

\subsection{Qualitative analysis}

The focus of the interviews was on investigating the teachers' stances regarding the two measures, their difficulty, content and aim. The analysis revealed that only 2 teachers in elementary and 1 in high school perceive tests as more difficult because students "must learn grammar rules and be able to apply them" (Participant 4). Contrary to this, 4 high school and 2 elementary school teachers claimed that learners face considerable difficulty when it comes to their performance in writing assignments, since, as one high school teacher said, students „must know everything in order to write." Therefore, the teachers generally view writing assignments more demanding for their students, being more complex in terms of the knowledge demonstrated. In addition to this, learners face difficulties with expressing their opinions and presenting their ideas in a writing assignment.

The analysis of the interviews also indicated that teachers have similar views when it comes to the test content and structure. The teachers stated they try to integrate vocabulary and grammar into contextual reading and writing exercises on tests, with the aim of developing their students' accuracy and fluency. Howev- 
er, accuracy seems to be prevalent as indicated both in the interviews and the analysis of the sample.

Most teachers stated they devote a lot of time to developing learners' explicit knowledge, be it either through inductive or deductive way, while students appear to be introduced with many metalinguistic terms, which is in accordance with previous research investigating Bosnian EFL context (Dubravac \& Pavičić Takač, 2013; Dubravac, 2013; Habibić \& Dubravac, 2017). All four elementary school teachers claimed they explain grammar rules and emphasize their importance in linguistic competence, as indicated in the following extract: "most of the time I usually present the rules and linguistic features and after that I do the exercises with the students" (Participant 6). Similarly, all high school teachers except one expect from their students to have a high level of explicit grammar knowledge, therefore, they explain all grammar rules to them explicitly. Some of the high school interviewees justified such an approach to teaching and evaluating students' knowledge stating they are much affected by the examination for the Higher School Certificate introduced in some cantons. Therefore, high school teachers feel obliged to bring their focus to grammar and accuracy, rather than fluency, to prepare the students for the written test based mostly on explicit grammar and vocabulary knowledge.

The analysis of the tests revealed similar findings since all of them comprised tasks related to explicit grammar knowledge, such as: fill in the gaps using the appropriate verb tense, or a verb form; complete the sentences with the correct pronouns; find mistakes in the sentences. Moreover, in most of them metalinguistic competence was expected since many technical terms were used in the introductory part of the tasks (e.g. what parts of speech are the words capitalized in the text; complete the sentences with appropriate passive forms; use narrative tenses; fill in the gaps with Present Perfect Simple or Present Perfect Continuous of the verbs; put nouns in plural), although metalanguage has been proved to be of little use in spontaneous way of communicating (Han \& Ellis, 1998). However, the teachers did not use tests to measure exclusively grammar knowledge but they also assessed their learners' knowledge of vocabulary including the following tasks: complete the sentences with words from the box; circle the correct word; answer the questions, define words and phrases; look at the pictures and write what animals are doing).

The tasks not related solely to grammar or vocabulary seemed to be included much less often. The only two other tasks found in the analyzed sample were a reading comprehension task (e.g. true or false; tick the correct answer), and a translation task (asking the students to translate sentences from Bosnian to English). Thus, grammar related questions were dominant in the tests given by all elementary and high school teachers, participating in the research.

A significant difference between high school and elementary school was not noticed with regard to tests. Teachers at both preferred to be very explicit and gave importance first to grammar features and then to vocabulary as well. However, 
their questions differed slightly in style. Elementary school teachers tended to appropriate their questions to young learners (e.g. look at the pictures and write what animals are doing; read about Fred's day), while high school teachers had a more formal approach (e.g. complete the sentence with an appropriate word). Nevertheless, the focus remained the same, and it could be said that tests for elementary school students represent a good basis and preparation for high school.

Another investigated type of assessment was a writing assignment, also known as an essay. According to our respondents in order to write an essay, learners need to possess a slightly higher level of linguistic knowledge. They need to be aware of the sentence formation, have a good command of English grammar, and a sufficient amount of acquired vocabulary. In other words, for their sentences to be appropriate, they need to have a good knowledge of words and their organization in the sentence.

The interviews revealed that teachers' primary aim is to use writing assignments in order to measure their students' overall knowledge of English, i.e. to measure fluency, accuracy as well as grammatical and lexical complexity. The emphasis in writing assignments is supposed to be on "syntax, lexis, fluency, coherence, and the use of pre-taught vocabulary items" (Participant 9). However, the most common drawback in educational system in BIH nowadays, according to our respondents, is the pressure parents and administration exert on them that makes them change their style of assessment and teaching in general. Due to low grades on the writing assignment examination when learners are not familiar with the topic prior to the examination date, teachers usually provide their students with two or more topics that they can prepare for before the exam, as demonstrated in the following excerpt from the interview.

When children were better and when they were aware of the importance of learning a language I used to give two or three topics in advance, and they were supposed to prepare one of these topics. However, nowadays, due to a great pressure from parents, administration and students I am forced to give them one topic in advance to ensure students' better grades regardless of their performance. (Participant 6)

The findings showed that although all teachers gave topic from the materials covered, two of them gave the exact topic, five teachers gave a few topics a week before the examination and chose only one for the writing assignment, and two teachers did not give a topic to students prior to examination. Consequently, a writing assignment might have ceased to be a reliable type of assessment due to the fact that a teacher might not be certain of learners' actual knowledge of English, since they might not be the ones who wrote the essay. Furthermore, the type of knowledge measured on them might be different. If students had got the title and limited time to write an essay they would have more likely relied on their implicit knowledge. However, with the topic given in advance and a lot of preparation writing assignments might have become as well a better measure of learners' explicit than their implicit knowledge (Ellis, R., 2005). 
The analysis of the feedback being provided on writing assignments showed a lot of similarities to the feedback provided on tests, although, in the interviews, the teachers stated they put more emphasis on fluency while evaluating the former. The overall perception of the interviewed teachers was that corrective feedback ought to be made, and that students are supposed to be provided with the correct form, because not all of them would be willing and motivated enough to find it themselves. By providing the correct form, teachers try to ensure that error fossilization is being prevented and they work on minimizing L1 interference. Furthermore, they see it as crucial that grammar errors are corrected on both assessment methods. In addition to this, one teacher admitted that slight subjectivity always exists in writing assignment assessment due to a couple of factors, such as the learner's style of writing, inborn creativity, and originality.

With regard to writing assignments, teachers in elementary schools explicitly corrected all students' errors by underlining incorrect forms, inserting omitted words, and crossing out unnecessary words. In addition to this, they tended to provide their students with a correct form and sentence composition, thus supporting the current trends suggesting that error correction leads to better accuracy (e.g. Chandler, 2000; Ferris, 1995; Sheppard, 1992). Teachers in elementary school paid a lot of attention to the affective factor when it comes to the evaluation itself, therefore, they provided some beneficial praise and commented their students' work, making the assessment more analytic (Bachta, 2001), i.e. process-oriented. Still, the analysis confirmed Gatbonton \& Sagalowitz's (2005) suggestion that teachers still pay more attention to accuracy than fluency since the evaluation of writing assignments was more form-focused than meaning-focused, with feedback generally related to accuracy, although teachers underlined some nonsensical or wrongheaded phrases and sentences.

On the other hand, high school teachers' evaluation was less form- focused. They might have considered that their students already had many years of formfocused instruction, therefore, they assumed that accuracy was an obligatory component. Likewise, they began paying attention to meaning and fluency. Their evaluation of writing assignment was not so explicit, rather their students received a grade without thorough feedback on their errors. Two high school teachers ${ }^{1}$ in this study used an online program, Edmodo, where learners posted their assignments for the evaluation and assessment, and where they could comment on one another's work. In that case, teachers and peers directly stated erroneous instances of language, gave their comment on the text, and suggested some of the ways in which cohesion could be improved. Their aim was to encourage peer-correction and to get knowledge and information from one another.

However, high school teachers' feedback on the tests was mainly explicit. They did not provide the correct answer, rather they marked students' answer as incor-

\footnotetext{
${ }^{1}$ Teachers from private high schools.
} 
rect and reduced their points. Thus, when students received their evaluated tests, they knew where they had made a mistake, however, they did not know what the correct answer was.

Therefore, although teachers generally focus more on forms than on the meaning, the evaluation of writing assignments seems more analytic and processoriented, especially in elementary schools. In writing assignments teachers provide comments and give advice to students on how to improve their writing, or which language elements to pay attention to on the next assignment, whereas on tests students just receive the number of points and the grade. Nonetheless, it seems that their errors do not remain completely unattended. It is a common practice that teachers devote one teaching hour to the correction of the test and writing assignment when the most common errors are analyzed together.

\subsection{Statistical analysis}

With the aim of investigating whether there was consistency in the grades students received on their tests and writing assignments, data was statistically analyzed. In the output presented in Table 2, the information we requested for each of the variables is summarized. The range of writing assignment grade was from 1 to 5 , with a mean of 4.11 and standard deviation of 1.178, while the range of test grade was also from 1 to 5 , with a mean of 3.19 and standard deviation of 1.364 .

Table 2. Descriptive statistics of the grades on tests and writing assignments

\begin{tabular}{cccccc}
\hline & $\mathrm{N}$ & Min & Max & Mean & SD \\
\hline Writing & 96 & 1 & 5 & 4.11 & 1.178 \\
$\begin{array}{c}\text { assignment } \\
\text { Test }\end{array}$ & 96 & 1 & 5 & 3.19 & 1.364 \\
\hline
\end{tabular}

In order to analyze whether there was a statistically significant difference between the grades students got on these two assessment methods, a paired samples $\mathrm{t}$-test was calculated. Its results $(\mathrm{t}(95)=7.523, \mathrm{p}=.000)$ suggested that there was a statistically significant difference between the grades students received on the test and writing assignment. The indications are, therefore, that students performed more poorly on the test, in comparison to their performance in the writing assignment.

There are several possible reasons for this. The first assumption could be that due to teachers' awareness of existing difficulties on writing assignment examination, they tried to award higher grades to students because of their creativity and originality. In addition to this, teachers had a greater opportunity to be subjective on the writing assignment examination, since tests were more objective and not rarely required only one accurate answer per question, whereas essays were more flexible. The third reason for the difference in grades might be the announcement 
of the topic prior to writing assignment examination, whereas, students were not aware of the questions included in the test. Being familiar with the topic of the writing assignment students were free to ask for help from adults and their peers. Moreover, they could search for some ideas on the internet, or consult some books. Either way, they were free to prepare the essay in advance and memorize it.

Having learned about the differences between the grades on tests and writing assignments, it is important to investigate whether the grades on each type of assessment differed based on school level. The grades on writing assignments between elementary and high school students were compared in order to determine whether there was a statistically significant difference in students' performance with regard to school level. The average grade on writing assignments for the elementary and high school students was 4 , with a mean score of 4.20 for elementary school, and 4.04 for the high school (see Table 3).

Table 3. Descriptive statistics of the grades on tests and writing assignments

\begin{tabular}{lcccccccc}
\hline & \multicolumn{3}{c}{$\begin{array}{c}\text { Elementary school } \\
(\mathrm{n}=45)\end{array}$} & & \multicolumn{5}{c}{$\begin{array}{c}\text { High school } \\
(\mathrm{n}=51)\end{array}$} \\
\hline Measure & $\mathrm{M}$ & SD & $\min$ & $\max$ & $\mathrm{M}$ & SD & $\min$ & $\max$ \\
\hline Test & 3.58 & 1.340 & 1 & 5 & 2.84 & 1.302 & 1 & 5 \\
WA & 4.20 & .944 & 1 & 5 & 4.04 & 1.356 & 1 & 5 \\
\hline
\end{tabular}

The independent samples t-test (Table 4 ), showed that $p=.507$, indicating no statistically significant difference in the average grade on the writing assignments between elementary and high school students. Students at both levels delivered similar performance, and were evaluated similarly on their writing assignments.

Table 4. Difference between grades on tests and writing assignments based on the school level (Independent samples t-test)

\begin{tabular}{lccc}
\hline Measure & t-value & $\mathrm{df}$ & $\mathrm{p}$ \\
\hline Writing assignment & .666 & 94 & .507 \\
Test & 2.722 & 94 & .008 \\
\hline
\end{tabular}

Following, the grades on tests were compared between elementary and high school students. The average grade of elementary school students on tests was 4 , with a mean score of 3.58, while for the high school students the average grade was 3, with a mean score of 2.84 (see Table 3). The independent samples t-test (Table 4 ) showed that $p=.008$, suggesting that there was a statistically significant difference in the grade on the test between elementary and high school students. The mean scores between test grades based on school level indicated that high school 
students received lower grades on tests than elementary school students. This might be attributed either to the fact that high school students had a poorer performance, or that teachers were more demanding when evaluating high school students' performance than elementary school teachers. Teachers in elementary schools tend to be more sensitive to students, whereas in high schools they train the students to become more independent learners, trying to prepare them for studies at the university level (see Matijević, 2005).

Interestingly, as we can see the difference was observed between the grades on tests but not between the grades on writing assignments. The claim that tests measure students' explicit knowledge and linguistic accuracy might be assumed as one of the main reasons for such findings. It might be that our participants from high schools spend less time studying the grammar rules than students in elementary school, and consequently they do not have explicit knowledge examined on tests. On the other hand, writing assignments do not require a lot of preparation since students are expected to apply their implicit knowledge, or in case they get the topic in advance they might ask for somebody else's help, which is why factors such as age may not be influencing students' performance on that type of assessment.

With the aim of investigating the relationship between the grades students received on tests and writing assignments a Pearson correlation test was used. Statistical information presented in Table 5 shows a strong ${ }^{2}$ positive correlation $(r=.557)$ between the students' grades on writing assignments and tests, which might indicate that teachers paid more attention to accuracy while evaluating both. Moreover, learners may have relied more on their explicit than implicit linguistic knowledge on both measures.

Table 5. Relationship between students' grades on tests and writing assignments

\begin{tabular}{lcc}
\hline Measure & Writing assignment & Test \\
\hline Writing assignment & - & $.557^{\star \star}$ \\
Test & - & - \\
\hline
\end{tabular}

**. Correlation is significant at the 0.01 level (2-tailed)

\section{Conclusion}

The main objective of the research was to explore the way in which foreign language knowledge is measured in Bosnian elementary and high schools by two measures, tests and writing assignments. The interviews revealed that teachers

\footnotetext{
${ }^{2}$ Cohen et al. (2004) r=.50 to 1.0 large correlation.
} 
conceive the writing assignment as a more integrative measure of learners' knowledge, while they see tests as suitable measures of grammar and vocabulary knowledge. As such tests might be used to measure learners' explicit knowledge and writing assignments to measure implicit linguistic knowledge.

The analysis confirmed teachers' stances regarding the tests, which mainly comprised tasks tapping into students' explicit knowledge. Thus, students' attention was focused on the form, they answered mainly relying on some grammar rules since the sentences were given out of the context and, furthermore, the use of metalinguistic knowledge was encouraged and expected. On the other hand, we learned that teachers prepare their students a lot for writing assessments, giving them either the exact topic or a few topics from which one would be chosen. This way the writing assignment might cease to measure learners' implicit knowledge, the students being allowed a lot of time to analyze the language and reflect on some rules. Moreover, they might ask somebody for help, and then just memorize the text.

Thus, taking into account the current trends of language learning and teaching there seems to be much space for improvement in terms of both measures. Tests should be more communicatively- oriented, based on fluency and meaning. The questions allowing students more spontaneous language use should be incorporated while metalanguage should be drastically reduced. As for writing assignments, in order to make them a suitable measure of learners' fluency and their implicit linguistic knowledge the exact topic should not be given in advance. Otherwise, the measure which has the capacity to tap into implicit knowledge is turned into a measure of explicit knowledge. Furthermore, although teachers include similar tasks in the tests, a choice of questions seems to be solely individual and varies with regard to teachers' preferences. The entire educational system should dictate the way students are prepared for and assessed on their English tests, since the test as one type of assessment, its content, and the way it is organized might direct the way English is taught and learned within language classrooms.

Teachers appear to correct learners' errors on both measures, which might significantly improve students' accuracy. However, what might and should be reconsidered is the focus of the feedback, which seems to be mainly on the form. Instead, writing assignments and some tasks on the tests might be also used to provide meaning-oriented feedback, leading more to fluency development. However, a wider context should be taken into account, since some teachers stated that they focus so much on explicit grammar knowledge to prepare their students better for the High School Certificate. This indicates that the changes related to the center of attention within language classrooms should be systematic.

Contrary to the teachers' beliefs, the statistics showed that grades on writing assignment tended to be higher than students' grades on tests, which might be attributed to several factors, none of which, unfortunately, seems to be the preva- 
lence of implicit over explicit knowledge. Teachers may be more flexible and subjective while grading writing assignments than when grading tests. Moreover, most of the students received topic prior to examination, which might have greatly affected their grades. In addition to this, the positive relationship between grades on test and written assignment adds to the conclusion that teachers paid more attention to linguistic accuracy than fluency on both types of assessment. However, assessing writing assignments seemed to be more process- oriented since teachers sometimes provided comments focusing on the improvement and advancement of their students, rather than on their proficiency level only, which was the case with tests.

Interestingly, there seemed to be no statistically significant difference between students' grades on writing assignments based on school level. However, a statistically significant difference was observed between the students' grades on tests based on school level, with high school students achieving lower mean score on tests than elementary school students. This might be attributed to the greater expectations on the part of high school teachers when assessing their students' knowledge demonstrated on tests. Furthermore, high school students may pay less attention to studying the rules, the knowledge of which is examined on tests.

Generally, the study suggests that both measures focus more on form and accuracy, i.e. explicit linguistic knowledge, both in the way in which they are realized, and in the way in which students' knowledge is assessed. The indications are, therefore, that, in addition to other researched aspects of Bosnian EFL context, this study confirms that there is much we can all do to give teaching and learning English a more communicative direction, thus utilizing the teaching hours more effectively and preparing students for the communicative use of language, which is the ultimate aim of language learning nowadays.

\section{References}

Anderson, John R. (1983). The architecture of cognition. Cambridge, MA: Harvard University Press.

Bacha, Nahla (2001). Writing evaluation: what can analytic versus holistic essay scoring tell us? System 29: 371-383.

Bialystok, Ellen (1982). On the relationship between knowing and using forms. Applied Linguistics 3: 181-206.

Brumfit, Christofer J. (1984). Communicative Methodology in Language Teaching. Cambridge University Press.

Chandler, Jean (2000). The efficacy of error correction for improvement in the accuracy of L2 student writing. Paper presented at the AAAL Conference, Vancouver, BC.

Chomsky, Noam (1965). Aspects of the Theory of Syntax. Cambridge, Massachusetts: The Massachusetts Institute Of Technology Press. 
Cohen, Jacob, Patricia Cohen, Stephen G. West, Leona S. Aiken (2004). Applied Multiple Regression/Correlation Analysis for the Behavioral Sciences. (3rd ed.). Hillsdale, NJ: Lawrence Erlbaum.

Corder, Stephen P. (1967). The significance of learners' errors. IRAL 5: 161-170.

DeKeyser, Robert (1997) Beyond explicit rule learning. Studies in Second Language Acquisition 19: 195-221.

Dubravac, Vildana, Višnja Pavičić Takač (2013). The relationship between complexity of linguistic structure and foreign language linguistic knowledge. Jezikoslovlje 14.2-3: 577-598.

Dubravac, Vildana (2013). Explicit and implicit knowledge with regard to the age of learners. ExELL 1.2: 166-186.

Ellis, Nick C. (2005). At the interface: dynamic interactions of explicit and implicit language knowledge. Studies in Second Language Acquisition 27: 305-352.

Ellis, Nick C. (2008). Implicit and explicit knowledge about language. In Cenoz, Jasone, Nancy H. Hornberger, eds. Encyclopedia of Language and Education. Vol. 6: Knowledge about Language. New York: Springer, 1-13.

Ellis, Rod (1994). A theory of instructed second language acquisition. Nick Ellis, ed. Implicit and Explicit Learning of Languages. London: Academic Press.

Ellis, Rod (2005). Measuring implicit and explicit knowledge of a second language: A psychometric study. Studies in Second Language Acquisition 27: 141-172.

Ferris, R. Dana (1995). Can advanced ESL students be taught to correct their most serious and frequent errors? CATESOL Journal 8.1: 41-62.

Gatbonton, Elizabeth, Norman Segalowitz (2005). Rethinking communicative language teaching: A focus on access to fluency. Canadian Modern Language Review 16.3: 325353.

Habibić, Ajša, Vildana Dubravac (forthcoming). Grammar acquisition in Bosnian EFL context. Pismo.

Han, Youngju, Rod Ellis (1998) Implicit knowledge, explicit knowledge and general language proficiency. Language Teaching Research 2: 1-23.

Housen, Alex, Folkert Kuiken (2009). Complexity, accuracy and fluency in second language acquisition. Applied Linguistics 30.4: 461-473.

Imamović, Adisa, Nihada Delibegović Džanić (2016). The status of English in Bosnia and Herzegovina: Past and present. Buckingham, Louisa, ed. The Status of English in Bosnia and Herzegovina. UK: Multilingual Matters, 9-31.

Krashen, Stephen (1982). Principles and Practice. Pergamon Press Inc.

Lennon, Paul (1990). Investigating fluency in EFL: A quantative approach. Language Learning 40: 387-417.

Lightbown, Patsy M, Nina Spada (2008). Form-Focused Instruction: Isolated or Integrated? TESOL Quarterly 42.2: 181-207.

Lightbown, Patsy M, Nina Spada, Lydia White (1993). The role of instruction in second language acquisition. Studies in Second Language Acquisition 15, 143-145.

Matijević, Milan (2005). Evaluacija u odgoju i obrazovanju. Pedagogijska istraživanja 2.2: 279298.

Muranoi, Hitoshi (2000). Focus on Form Through Interaction Enhancement: Integrating Formal Instruction Into a Communicative Task in EFL Classrooms. Language Learning 50.4: 617-673. 
O'Grady, William, John Archibald, Francis Katamba (2011). Contemporary Linguistics: An Introduction. Edinburgh Gate: Pearson Education Limited.

Ortega, Lourdes (2009). Second Language Acquisition. London: Hodder Education.

Schmidt, Richard (2010). Attention, awareness, and individual differences in language learning. Wai Meng Chan, Seo Chi, K. N. Cin, J.ohanna W. Istanto, Masanori Nagami, Jyh W. Sew, Titima Suthiwan, Izumi Walker, eds. Proceedings of CLaSIC 2010. Singapore: National University of Singapore, Centre for Language Studies 721737.

Sheppard, Ken (1992). Two feedback types: Do they make a difference? RELC Journal 23: 103-110.

Sternberg, Robert, Elena Grigorenko (1997). Are cognitive styles still in style? American Psychologist 52: 700-712.

Wolfe-Quintero, Kate, Shjunji Inagaki, Hae-Young Kim (1998). Second language development in writing: Measures of fluency, accuracy and complexity (Technical Report No. 17). Honolulu: University of Hawai'i, Second Language Teaching and Curriculum Center.

\section{Authors' addresses:}

Ana Tankosić

Vildana Dubravac

International Burch University

Francuske revolucije bb,

71210 Ilidža

Sarajevo, Bosnia and Herzegovina

E-mail: ana.tankosic@ibu.edu.ba

vildana.dubravac@ibu.edu.ba

Received: March 9, 2017

Accepted for publication: April 19, 2017 